\title{
Effect of cytokinins on shoots proliferation and rosmarinic and salvianolic acid B production in shoot culture of Dracocephalum forrestii W. W. Smith
}

\author{
Izabela Weremczuk-Jeżyna ${ }^{1}$ • Łukasz Kuźma ${ }^{1}$ • Anna K. Kiss ${ }^{2}$ · Izabela Grzegorczyk-Karolak ${ }^{1}$
}

Received: 23 January 2018 / Revised: 28 September 2018 / Accepted: 9 October 2018 / Published online: 17 October 2018

(c) The Author(s) 2018

\begin{abstract}
The current study estimates the effect of different cytokinins on shoot proliferation and biosynthesis of caffeic acid derivatives in Dracocephalum forrestii in vitro culture. The shoots were grown on Murashige and Skoog (MS) agar medium with $1 \mu \mathrm{M}$ indole-3-acetic acid (IAA) and different content of 6-benzyloaminopurine (BAP), zeatin, kinetin $(1,2,4,8,18 \mu \mathrm{M})$ or thidiazuron (TDZ) $(0.1,0.2,0.5,1,2 \mu \mathrm{M})$. The highest multiplication rate (about seven shoots and/or buds per explant) was obtained after 4 weeks of culture on MS medium with $1 \mu \mathrm{M}$ IAA and 8 or $16 \mu \mathrm{M}$ BAP. Optimal biomass of plant material was also received on the same media. The identity of the compounds present in the hydromethanolic extracts from $D$. forrestii shoots grown on cytokinin-supplemented media was confirmed using UPLC-PDA-ESI-MS method. The analysis revealed the presence of nine metabolites recognized as caffeic acid derivatives. The content of the predominant phenolic acids in the extracts, i.e. rosmarinic acid (RA) and salvianolic acid B (SAB), was determined with UHPLC. The highest yield of RA was found in shoots cultivated in the medium containing $1 \mu \mathrm{M}$ IAA and $2 \mu \mathrm{M}$ BAP $(18.7 \mathrm{mg} / \mathrm{g} \mathrm{DW})$. The highest level of SAB $(5.3-5.9 \mathrm{mg} / \mathrm{g} \mathrm{DW})$ was identified in multiple shoots grown in the presence of $1 \mu \mathrm{M}$ IAA and $0.5-1 \mu \mathrm{M}$ TDZ or $2 \mu \mathrm{M}$ BAP.
\end{abstract}

Keywords Shoot proliferation $\cdot$ Cytokinin $\cdot$ Rosmarinic acid $\cdot$ Salvianolic acid B

\begin{tabular}{ll}
\multicolumn{2}{l}{ Abbreviations } \\
BAP & 6-Benzyloaminopurine \\
IAA & Indole-3-acetic acid \\
TDZ & Thidiazuron \\
RA & Rosmarinic acid \\
SAB & Salvianolic acid B
\end{tabular}

\section{Introduction}

Dracocephalum forrestii W. W. Smith (Lamiaceae) is a medicinal herbaceous plant naturally grown in China, specifically in the northwest of the Yunnan province (Li et al.

Communicated by P. Wojtaszek.

Izabela Grzegorczyk-Karolak

izabela.weremczuk-jezyna@umed.lodz.pl

1 Departament of Biology and Pharmaceutical Botany, Medical University of Lodz, Muszyńskiego 1, Lodz, Poland

2 Department of Pharmacognosy and Molecular Basis of Phytotherapy, Medical University of Warsaw, Banacha 1, Warsaw, Poland 2009b). Its antipyretic, diuretic and astringent properties have been used in Tibetan medicine for centuries ( $\mathrm{Li}$ et al. 2007, 2009b). The pharmacological activities of $D$. forrestii are mainly associated with the contents of numerous secondary metabolites such as mono- and triterpenoids, flavonoids and phenolic acids, including caffeic acid derivatives ( $\mathrm{Li}$ et al. 2007, 2009b).

Phenolic compounds have been widespread in the plant kingdom, in particular, in the Lamiaceae and Boraginaceae families (Petersen 2013). Chlorogenic acid, caffeic acid, rosmarinic acid and its dimer, salvianolic acid B have earlier been identified in Dracocephalum species (WeremczukJeżyna et al. 2016; Zeng et al. 2010; Li et al. 2009b). The biological properties of phenolic acids have been extensively studied for many recent years (Bulgakov et al. 2012), and have been found to exhibit anti-inflammatory, antiviral, antibacterial and antioxidant activity (Petersen 2013; Cao et al. 2012). Furthermore, rosmarinic acid and salvianolic acid B show cancer chemoprevention and antifibrotic effect. The substances are known to be effective in the therapy of cerebrovascular disorders and rheumatoid arthritis ( $\mathrm{Li}$ et al. 2010; Hur et al. 2007; Inyunshina et al. 2007; Jaiong et al. 2005). 
The pharmacological value of polyphenolic acids has driven efforts to identify new high-quality natural sources. One possible approach employs the use of in vitro plant culture. Biotechnological methods allow pharmacologically important substances to be produced at high level within controlled laboratory environments (Tisserot and Vanghn 2008). The use of in vitro plant cultures for the production of caffeic acid derivatives has been widely described for the species of the Lamiaceae (Bulgakov et al. 2012). In the genus Dracocephalum, biosynthesis of rosmarinic acid has been reported for transformed root cultures of D. moldavica, D. forrestii and D. kotschyi (Weremczuk-Jeżyna et al. 2013, 2016; Fattahi et al. 2013). In addition, a particularly high content of salvianolic acid B was detected in hairy roots and cell suspension culture of Salvia miltiorrhiza (Dong et al. 2010; Xiao et al. 2010), as well as the transformed roots of $D$. forrestii and Ocimum basilicum (Weremczuk-Jeżyna et al. 2016; Tada et al. 1996). Plant tissue culture can be used to increase the biosynthesis of plant metabolites by modifying culture conditions. One important factor reported to influence plant propagation and secondary metabolite accumulation is the profile of the growth regulators in the medium (Grzegorczyk-Karolak et al. 2015; Piątczak et al. 2015; Collin 2001).

The aim of the current work was to determine the optimal conditions for $D$. forrestii shoot culture with regard to the cytokinins composition and their concentration in the medium, by measuring the degree of effective shoot multiplication and biosynthesis of rosmarinic acid and salvianolic acid B. For comparison, RA and SAB levels in shoots of 1 -year-old plants grown in field were evaluated.

\section{Materials and methods}

\section{Plant material}

The Dracocephalum forrestii shoot cultures were initiated from seeds received from Parco Nazionale Gran Paradiso, Valnontey (Italy). The seeds were surface sterilized with sodium hydrochloride solution (2\%) for $3 \mathrm{~min}$ and next washed (three times) using sterilized water. The seeds were carried on MS (Murashige and Skoog 1962) agar (0.7\%) medium contained $0.5 \mu \mathrm{M}$ kinetin and $2.5 \mu \mathrm{M}$ gibberellic acid and incubated in the dark. After germination, the shoot tips (0.3-0.5 cm long) resected from 4-week-old seedlings were carried into glass tubes with $25 \mathrm{ml} \mathrm{MS}$ agar medium with $0.5 \mu \mathrm{M}$ IAA and $1 \mu \mathrm{M}$ BAP for shoot proliferation. After 4 weeks, for elongation, the formed shoots were placed into MS medium without growth regulators. The shoots (4-5 cm long) were source of explants (nodal segments) for further experiments. The cultures grown at $26 \pm 2{ }^{\circ} \mathrm{C}$ under a 16 photoperiod (cool white fluorescent lamps; $40 \mu \mathrm{m} / \mathrm{m}^{2} / \mathrm{s}$ ).

\section{Effect of cytokinins on shoot multiplication and biomass production}

Nodal segments (about $0.5 \mathrm{~cm}$ length) (Fig. 1a) from shoots grown in vitro (10-12 subcultures) were transferred onto MS agar medium supplemented with IAA $(1 \mu \mathrm{M})$ and kinetin, zeatin, $\mathrm{BAP}(1,2,4,8,16 \mu \mathrm{M})$ or TDZ $(0.1,0.2,0.5,1$ or $2 \mu \mathrm{M})$. Control explants were grown on MS medium supplemented only with auxin ( $1 \mu \mathrm{M}$ IAA). After 4 weeks of growth, the percentage of nodal segments forming shoots and/or buds and their average number per explant were recorded. Additionally, the fresh (FW) and dry weight (DW) (g/tube) of obtained shoots were estimated. The percentage of hyperhydric shoots were also evaluated. The experiments were repeated three times, a total of 30 nodal segments were used for each cytokinin type and concentration.

\section{Extraction and determination of phenolic acids}

\section{Preparation of extracts}

Plant material (100 mg) lyophilized and next powdered, was first extracted with chloroform $(15 \mathrm{ml})$. After filtration, the sample was sonicated (ultrasonic disintegrator type UD-20) for 15 min with $80 \%$ (v/v) aqueous methanol $(25 \mathrm{ml})$ at $40{ }^{\circ} \mathrm{C}$. Then, the hydromethanolic extraction process with was repeated twice with $10 \mathrm{ml}$ of the solvent. After filtration, the extracts were connected and vaporized to dryness under reduced pressure.

\section{Qualitative UPLC-PDA-ESI-MS analysis}

In a present study, a UHPLC-3000 RS system (Dionex, Germany) with PAD detection and an AmaZon SL ion trap mass spectrometer with ESI interface (Bruker Daltonik $\mathrm{GmbH}$, Germany) were used. Separation was performed on a Zorbax SB C18 column (Agilent, USA) according to the method described in our earlier study (WeremczukJeżyna et al. 2016). Compounds were analyzed in negative ion mode. The phenols were detected at $328 \mathrm{~nm}$ and identified by comparison of the retention times, UV and mass spectra of the peaks with those of the reference compounds (Sigma-Aldrich) and published data (Ncube et al. 2014; Nuenchamong et al. 2011; Liu et al. 2007a, b; Zeng et al. 2006). 
Fig. 1 Initial nodal explant of D. forrestii (a); 4-week-old shoots of $D$. forrestii regenerated on MS medium supplemented with $1 \mu \mathrm{M}$ IAA and cytokinin: $8 \mu \mathrm{M}$ BAP (b), $2 \mu \mathrm{M}$ BAP $(\mathbf{c}), 1 \mu \mathrm{M}$ zeatin $(\mathbf{d})$, $16 \mu \mathrm{M}$ kinetin (e) or $0.5 \mu \mathrm{M}$ TDZ (f). Bar $-1 \mathrm{~cm}$
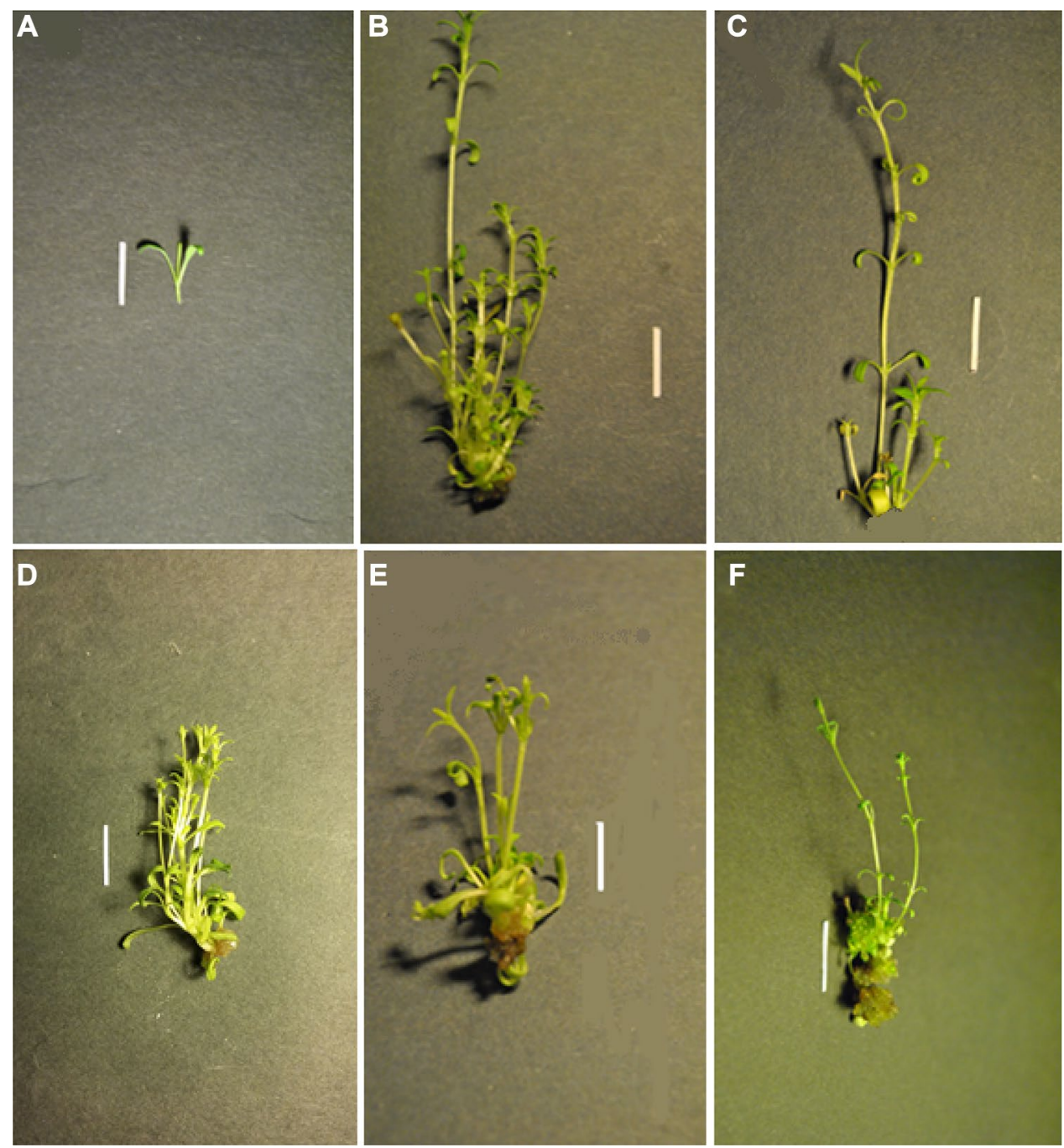

\section{Quantitative analysis of rosmarinic acid and salvianolic acid B}

The samples were dissolved in $2 \mathrm{ml}$ of methanol and the content of phenols in extracts were analyzed by UHPLC method as described earlier (Weremczuk-Jeżyna et al. 2016). Chromatographic system that used in this study was an Agilent Technologies 1290 Infinity UHPLC apparatus equipped with Zorbax Eclipse C18 Column $(100 \times 3.1 \mathrm{~mm}$ id, $1.8 \mu \mathrm{m}$; Agilent Technologies).

The shoots of plants obtained from the same seeds as in vitro culture and grown for 1 year under field conditions in Garden of the Department of Pharmacognosy at Medical University of Lodz were collected for comparative secondary metabolite analysis. The levels of the compounds in the analyzed extracts were expressed as $\mathrm{mg} / \mathrm{g}$ dry weight (DW). The results are presented in Figs. 2 and 3.

\section{Statistical analysis}

All results are expressed as the mean \pm standard error (SE). The means were analyzed for statistical significance of differences by the Kruskal-Wallis test, with results of $p \leq 0.05$ being considered significant (Statistica 10.0. Statsoft, Poland).

\section{Results and discussion}

\section{Effect of cytokinins on shoot proliferation}

An efficient protocol for proliferation of $D$. forrestii was development and multiple shoots were obtained by culturing nodal explants on MS medium supplemented with $1 \mu \mathrm{M}$ IAA and different type and concentrations of cytokinins: 
Fig. 2 The effect of various cytokinins and their concentrations on rosmarinic acid accumulation in $D$. forrestii shoots. Control-shoots cultivated on MS medium only with IAA $1 \mu \mathrm{M}$. The results are expressed as means of three replicates $\pm \mathrm{SE}$. The means with the same letter do not differ significantly according to the Kruskal-Wallis test $(p \leq 0.05)$
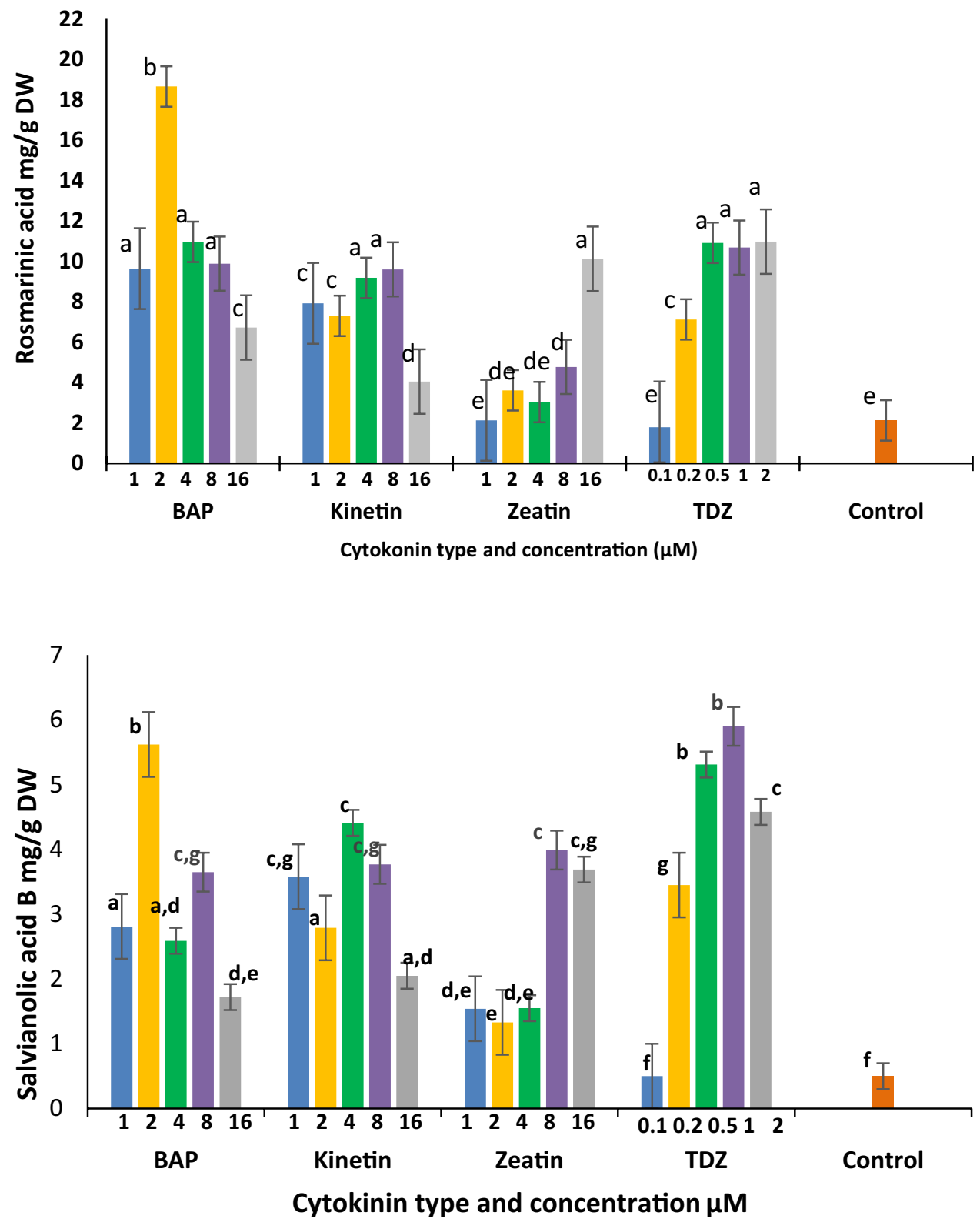

BAP, zeatin, kinetin or TDZ. There are many in vitro studies reported using nodal explants for the propagation of plants from the Lamiaceae family (Otroshy and Moradi 2013; Rani et al. 2006; Ghandi et al. 2004). The effect of the cytokinins on shoot proliferation, fresh and dry weight production was evaluated after 4 weeks of culture, as was the morphology of the D. forrestii shoots. The results are presented in Table 1.

The multiplication response of nodal explants, expressed as new shoots and buds formation, ranged from 83 to $100 \%$ and was not very dependent on the type and concentration of growth regulators in the medium (Table 1). A very high response was also noted for the control shoots growing on MS medium with $1 \mu \mathrm{M}$ IAA (93\%). BAP at concentrations of 8 and $16 \mu \mathrm{M}$ was the most effective for shoot proliferation, resulting in about seven shoots or buds per explant within 4 weeks of culture, with most of the forming shoots showing normal morphology without malformations or hyperhydricity (Fig. 1b; Table 1). However, the multiplication rate at lower BAP concentrations $(1,2,4 \mu \mathrm{M})$ was about three times lower (1.8-2.7 shoots) (Fig. 1c). Similarly, Otroshy and Moradi (2013) obtained the highest number of Dracocephalum kotshyi shoots (about seven shoots per explant) on medium contained $2 \mathrm{mg} / \mathrm{l}$ (about $8 \mu \mathrm{M}$ ) BAP. Medium with lower content, $1 \mathrm{mg} / \mathrm{l}(4 \mu \mathrm{M}) \mathrm{BAP}$ was significantly less effective, giving about five shoots/explant. Also, Mehta et al. (2012) and Rani et al. (2006) reported that medium with addition of $2 \mathrm{mg} / \mathrm{l}$ BAP was optimal for shoot multiplication of two other Lamiaceae species: Mentha piperita and Coleus blumei. 
Table 1 Influence of cytokinins on D. forrestii shoot proliferation

\begin{tabular}{|c|c|c|c|c|c|}
\hline Cytokinins $(\mu \mathrm{M})$ & $\begin{array}{l}\% \text { of explants producing } \\
\text { axillary shoots and/or buds }\end{array}$ & $\begin{array}{l}\text { Total number of } \\
\text { axillary shoots and } \\
\text { buds } \pm \text { SE }\end{array}$ & $\begin{array}{l}\% \text { of malformed and/ } \\
\text { or hyperhydrous shoots }\end{array}$ & Fresh weight (g/tube) & Dry weight (g/tube) \\
\hline \multicolumn{6}{|l|}{ Zeatin } \\
\hline 1 & 90 & $4.5 \pm 1.22^{\mathrm{b}}$ & 8.3 & $2.23 \pm 0.3^{\mathrm{a}}$ & $0.33 \pm 0.02^{\mathrm{a}}$ \\
\hline 2 & 93.3 & $3.9 \pm 0.68^{\mathrm{b}}$ & 0 & $1.93 \pm 0.04^{\mathrm{a}, \mathrm{f}}$ & $0.28 \pm 0.03^{\mathrm{a}}$ \\
\hline 4 & 83.3 & $3.1 \pm 0.74^{\mathrm{c}}$ & 24.2 & $1.08 \pm 0.03^{\mathrm{b}}$ & $0.21 \pm 0.02^{\mathrm{b}}$ \\
\hline 8 & 100 & $1.8 \pm 0.58^{\mathrm{d}}$ & 0 & $0.93 \pm 0.01^{\mathrm{b}}$ & $0.19 \pm 0.02^{\mathrm{b}}$ \\
\hline 16 & 90 & $2.0 \pm 0.34^{\mathrm{d}}$ & 0 & $1.01 \pm 0.01^{\mathrm{b}}$ & $0.20 \pm 0.01^{\mathrm{b}}$ \\
\hline \multicolumn{6}{|l|}{ Kinetin } \\
\hline 1 & 83.3 & $3.2 \pm 0.51^{\mathrm{c}}$ & 19.7 & $2.12 \pm 0.01^{\mathrm{a}}$ & $0.31 \pm 0.03^{\mathrm{a}}$ \\
\hline 2 & 96.7 & $3.3 \pm 0.42^{c}$ & 12.4 & $2.14 \pm 0.05^{\mathrm{a}}$ & $0.31 \pm 0.02^{\mathrm{a}}$ \\
\hline 4 & 86.2 & $3.2 \pm 0.57^{\mathrm{c}}$ & 7.9 & $2.25 \pm 0.04^{\mathrm{a}}$ & $0.34 \pm 0.01^{\mathrm{a}}$ \\
\hline 8 & 90.0 & $2.7 \pm 0.11^{\mathrm{c}, \mathrm{e}}$ & 4.5 & $2.12 \pm 0.01^{\mathrm{a}}$ & $0.32 \pm 0.01^{\mathrm{a}}$ \\
\hline 16 & 85.0 & $4.5 \pm 0.32^{\mathrm{b}}$ & 14.4 & $3.2 \pm 0.01^{\mathrm{c}}$ & $0.48 \pm 0.03^{\mathrm{c}}$ \\
\hline \multicolumn{6}{|l|}{ BAP } \\
\hline 1 & 93.3 & $1.8 \pm 0.38^{\mathrm{d}}$ & 8.3 & $0.93 \pm 0.01^{\mathrm{b}}$ & $0.13 \pm 0.01^{\mathrm{d}}$ \\
\hline 2 & 93.1 & $2.4 \pm 0.31^{\mathrm{e}}$ & 0 & $1.32 \pm 0.02^{\mathrm{d}}$ & $0.21 \pm 0.02^{\mathrm{b}}$ \\
\hline 4 & 83.3 & $2.7 \pm 0.5^{\mathrm{c}}$ & 14.4 & $1.29 \pm 0.05^{\mathrm{d}}$ & $0.20 \pm 0.05^{\mathrm{b}}$ \\
\hline 8 & 86.7 & $6.8 \pm 0.21^{\mathrm{a}}$ & 7.06 & $3.51 \pm 0.01^{\mathrm{e}}$ & $0.53 \pm 0.01^{\mathrm{c}}$ \\
\hline 16 & 85.5 & $6.9 \pm 0.13^{\mathrm{a}}$ & 7.24 & $3.45 \pm 0.03^{\mathrm{c}, \mathrm{e}}$ & $0.49 \pm 0.03^{\mathrm{c}}$ \\
\hline \multicolumn{6}{|l|}{ TDZ } \\
\hline 0.1 & 96.7 & $2.7 \pm 0.53^{c}$ & 2.9 & $1.37 \pm 0.03^{\mathrm{d}}$ & $0.22 \pm 0.01^{\mathrm{b}}$ \\
\hline 0.2 & 93.3 & $2.2 \pm 0.32^{\mathrm{d}, \mathrm{e}}$ & 22.7 & $1.64 \pm 0.05^{\mathrm{d}, \mathrm{f}}$ & $0.25 \pm 0.02^{\mathrm{a}, \mathrm{b}}$ \\
\hline 0.5 & 93.3 & $2.8 \pm 0.52^{\mathrm{c}}$ & 23.5 & $1.43 \pm 0.01^{\mathrm{d}}$ & $0.21 \pm 0.01^{\mathrm{b}}$ \\
\hline 1 & 86.7 & $2.2 \pm 0.41^{\mathrm{d}, \mathrm{e}}$ & 21.8 & $1.80 \pm 0.01^{\mathrm{f}}$ & $0.27 \pm 0.02^{\mathrm{a}, \mathrm{b}}$ \\
\hline 2 & 100 & $2.3 \pm 0.31^{\mathrm{d}, \mathrm{e}}$ & 8.7 & $1.12 \pm 0.02^{\mathrm{b}}$ & $0.18 \pm 0.01^{\mathrm{b}}$ \\
\hline \multicolumn{6}{|l|}{ Control } \\
\hline- & 93.0 & $1.7 \pm 0.09^{\mathrm{d}}$ & 0 & $0.42 \pm 0.01^{\mathrm{g}}$ & $0.12 \pm 0.02^{\mathrm{d}}$ \\
\hline
\end{tabular}

Control-shoots cultivated on MS medium only with IAA $1 \mu \mathrm{M}$. The values represented the mean \pm SE of three independent experiments. Means followed by the same letter within the column were not significantly different $(p \leq 0.05)$ according to the Kruskal-Wallis test

The multiplication rate obtained for $D$. forrestii shoots in the presence of zeatin and kinetin was lower than observed under optimal conditions (BAP at concentration 8 and $16 \mu \mathrm{M}$ ) (Table 1). However, with the exception of the highest zeatin levels $(8-16 \mu \mathrm{M})$, these cytokinins gave significantly better results for shoot multiplication than the control medium without cytokinin. For example, about 3.9-4.5 regenerated shoots per explants were observed after 4 weeks of culture on media containing 1 and $2 \mu \mathrm{M}$ zeatin (Fig. 1d) and $16 \mu \mathrm{M}$ kinetin (Fig. 1e). TDZ proved particularly unfavorable for shoot multiplication. Not only was the propagation rate of explants grown on media with this cytokinins were quite low (2.2-2.8 shoot per explant) (Fig. 1f), but also numerous shoots obtained in this conditions were malformed or hyperhydric (to $24 \%$ ). It has often been observed that BAP is more effective for shoot proliferation than other cytokinins. MS medium supplemented with $2 \mathrm{mg} / \mathrm{l} \mathrm{BAP}$ gave better results for $D$. kotschyi shoot propagation than a medium with the same concentration of kinetin (Otroshy and Moradi 2013). Similar results were achieved for Mentha piperita and Scutellaria altissima (Grzegorczyk-Karolak et al. 2017; Mehta et al. 2012).

The cytokinin supplementation of MS medium also increased the biomass of $D$. forrestti culture after 4 weeks of growth (Table 1). The greatest fresh (FW) and dry (DW) biomass values were obtained for $D$. forrestii shoots grown on media with 8 and $16 \mu \mathrm{M}$ BAP; about $3.5 \mathrm{~g} \mathrm{FW/tube} \mathrm{and}$ $0.5 \mathrm{~g} \mathrm{DW} /$ tube. Similar results were achieved for shoots cultured on medium containing $16 \mu \mathrm{M}$ kinetin (no statistical differences) (Table 1). Also, Fraternale et al. (2003) for Thymus mastichina and Affonso et al. (2009) for Thymus vulgaris observed maximum biomass of micropropagated plants on media supplemented with BAP. Whereas the highest dry and fresh biomass of Salvia officinalis culture were found on media containing kinetin (Santos-Gomes and Fernandes-Ferreira 2003). 


\section{Identification of phenolic compounds of the hydromethanolic extract of $D$. forrestii}

A hydromethanolic extract was prepared from the $D$. forrestii in vitro shoots, and its phenolic profile was investigated by UHPLC-PDA-ESI-MS ${ }^{3}$ analysis. All analyzed samples of shoot cultures presented a similar qualitative profile comprising nine peaks, four $(1,2,6,8)$ of which were identified by comparing their data (retention times-Rt, UV-Vis absorption spectra, and MS/MS fragmentation patterns) with those of reference standards. Other compounds for which standards were not available were identified by analysis their MS/MS spectral characteristic and confirmed with literature data (Catarino et al. 2015; Carlotto et al. 2015; Wang et al. 2012; Lecompte et al. 2010; Liu et al. 2007a; Kuo et al. 2000). The properties of the examined compounds and representative HPLC-UV chromatograms are presented in Table 2 and Fig. 4.

In the MS spectra, peak 1 corresponded to a pseudomolecular ion $[\mathrm{M}-\mathrm{H}]^{-}$at $\mathrm{m} / \mathrm{z}, 353$ and a fragment ion at $\mathrm{m} / \mathrm{z}$
191 formed from deprotonated quinic acid. This peak was identified as chlorogenic acid (Chen et al. 2014; Yang et al. 2012). Peak 2 indicated a pseudomolecular ion $[\mathrm{M}-\mathrm{H}]^{-}$at $\mathrm{m} / \mathrm{z}$ 179, identified as caffeic acid (Chen et al. 2014; Bravo et al. 2007). Peak 3 corresponded to a prominent $[\mathrm{M}-\mathrm{H}]^{-}$ion at $\mathrm{m} / \mathrm{z} 537$. The presence of fragment ions $[\mathrm{M}-\mathrm{H}]^{-}$at $\mathrm{m} / \mathrm{z} 339$, 295 and 493 suggested that the danshensu moiety (3,4-dihydroxyphenyllactic acid) was lost in the first place (- 198 $\mathrm{amu}$ ) and that the carboxyl(- $44 \mathrm{amu})$ was detached; this may indicate that the compound contains no furan moiety. Such a MS spectrum is characteristic for salvianolic acid $\mathrm{H}$ or I, which have the same molecular weight (538) and mass spectra patterns (Liu et al. 2007a). Peak 4 indicated a pseudomolecular $[\mathrm{M}-\mathrm{H}]^{-}$ion at $\mathrm{m} / \mathrm{z} 717$, and a fragment ion at $m / z 519[\mathrm{M}-\mathrm{H}]^{-}$as the result of the disconnection of a danshensu unit (- $198 \mathrm{amu})$. Elution order and the literature data identify the compound as salvianolic acid $\mathrm{E}$ (Wang et al. 2012). Peak 5 showed a base ion $[\mathrm{M}-\mathrm{H}]^{-}$at $\mathrm{m} / \mathrm{z} 515$ with a major fragment at $\mathrm{m} / \mathrm{z} 353(-162 \mathrm{amu})$ which in turn exhibited ions at $m / z 191$ and 179. A comparison with the

Table 2 Retention time, UV and MS/MS data of the compounds present in hydromethanolic extracts of $D$. forrestii

\begin{tabular}{llllll}
\hline Peak no. & $\begin{array}{l}\text { Retention } \\
\text { time }(\min )\end{array}$ & $\lambda_{\max }(\mathrm{nm})$ & \multicolumn{2}{l}{ Negative Ion mode } & Compound \\
\cline { 3 - 4 } & & 331 & 353 & 191 & \\
\hline 1 & 17.1 & 323 & 179 & & Chlorogenic acid \\
2 & 19.3 & 288 & 537 & $493, \mathbf{3 3 9}, 295$ & Caffeic acid \\
3 & 34.5 & $214,237,330$ & 717 & 519 & Salvianolic acid I/H \\
4 & 34.6 & $218,516,326$ & 515 & $\mathbf{3 5 3}, 191,179$ & Dalvianolic acid E \\
5 & 34.9 & $179,285,329$ & 359 & $197, \mathbf{1 6 1}$ & Rosmarinic acid \\
6 & 37.4 & $225,285,310$ & 537 & $\mathbf{4 9 3}, 295$ & Lithospermid \\
7 & 39.0 & $257,286,308$ & 717 & $\mathbf{5 1 9}, 321$ & Salvianolic acid B \\
8 & 41.7 & 287,326 & 373 & $\mathbf{1 7 9}, 135$ & Methyl rosmarinate \\
9 & 44.0 & & & & \\
\hline
\end{tabular}

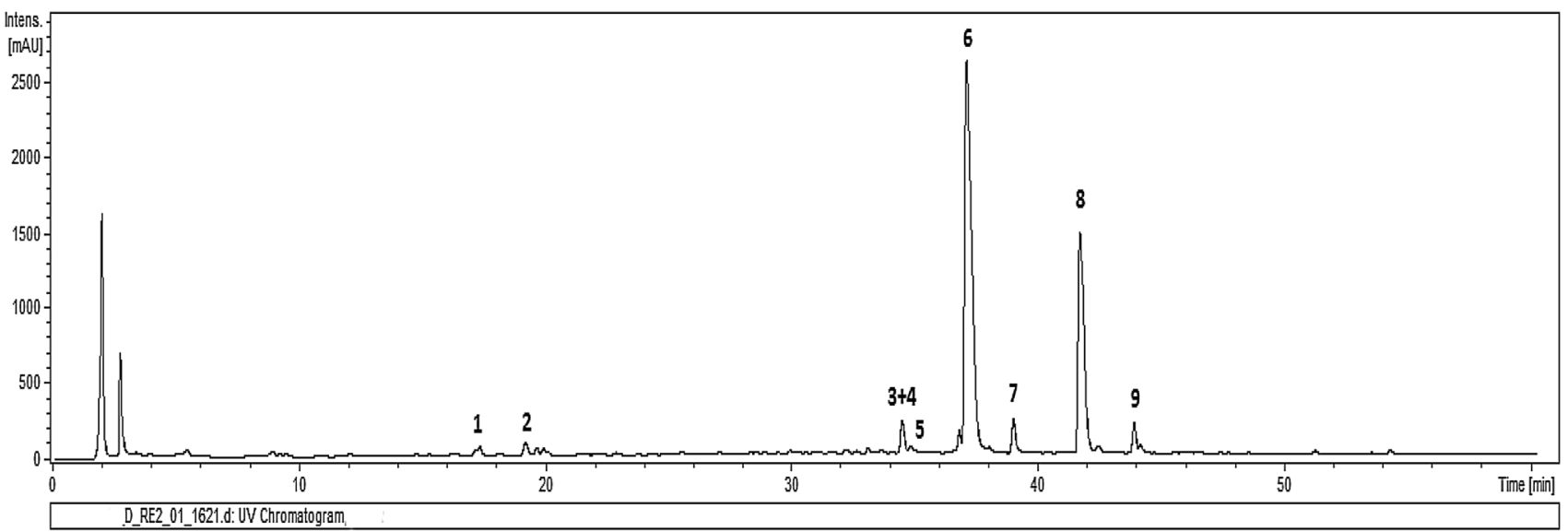

Fig. 4 Chromatogram of hydromethanolic extract of $D$. forrestii shoots grown on MS medium with IAA and BAP. (1) chlorogenic acid, (2) caffeic acid, (3) salvianolic acid I/H, (4) salvianolic acid E,
(5) dicaffeoylquinic acid, (6) rosmarinic acid, (7) lithospermic acid A, (8) salvianolic acid B, (9) methyl rosmarinate 
literature data suggests that compound $\mathbf{5}$ is dicaffeoylquinic acid (Catarino et al. 2015; Carlotto et al. 2015). Similarly, peak 6 was identified as rosmarinic acid by comparisons with standards and literature data (Ncube et al. 2014; Nuenchamong et al. 2011; Liu et al. 2007a, b; Zeng et al. 2006). The fragmentation patterns revealed the presence of pseudomolecular ion $[\mathrm{M}-\mathrm{H}]^{-}$at $\mathrm{m} / z, 359$ and $\mathrm{MS}^{2}$ base ion at $\mathrm{m} / \mathrm{z} 161[\mathrm{M}-\mathrm{H}]^{-}$, formed by elimination (- $198 \mathrm{amu}$ ) of a danshensu moiety. In negative mode, the ESI-MS analysis peak 7 corresponded to a pseudomolecular ion $[\mathrm{M}-\mathrm{H}]^{-}$at $\mathrm{m} / \mathrm{z}$ 537. This compound lost a carboxyl group, releasing a fragment at $\mathrm{m} / \mathrm{z} 493[\mathrm{M}-\mathrm{H}]^{-}$, that gave further ions at $\mathrm{m} / \mathrm{z}$ 295. Based on the literature data, compound 7 could indicate to lithospermic acid A (Ribeiro et al. 2016). Compound 8 gave a pseudomolecular ion at $\mathrm{m} / z 717[\mathrm{M}-\mathrm{H}]^{-}$. The presence of a specific MS2 pattern with ion fragments at $\mathrm{m} / \mathrm{z} 519$ $[\mathrm{M}-\mathrm{H}]^{-}$and $321[\mathrm{M}-\mathrm{H}]^{-}$formed by loss of two danshensu units, reveals the presence of two rosmarinic acid molecules linked via the aromatic ring of caffeic acid of a benzofuran structure: a linkage characteristic of a tetramer structure. A comparison of the MS spectra with authentic standards indicates that compound 8 is salvianolic acid B (Liu et al. 2007a, b; Zeng et al. 2006). Peak 9, corresponded to the presence of a pseudomolecular ion $[\mathrm{M}-\mathrm{H}]^{-}$at $\mathrm{m} / \mathrm{z}$ 373. Fragmentation of molecular ion leads to ions at $\mathrm{m} / \mathrm{z}, 179$ and 135, corresponding to the deprotonated form of caffeic acid and its residue after decarboxylation. Compound $\mathbf{9}$ was classified as methyl rosmarinate based on the literature data (Lecompte et al. 2010; Kuo et al. 2000).

Phenolic acids such as caffeic acid, chlorogenic acid and rosmarinic acid and their derivatives are widespread in the Lamiceae family (Petersen 2013). These secondary metabolites have also been described in the Dracocephalum genus (Zeng et al. 2010). Li et al. (2009a, b) identified more than sixty compounds belonging to different chemical groups in ethanolic extracts from whole plants of $D$. forrestii. Most compounds were monoterpenes, but the authors also described caffeic acid derivatives such as caffeic acid and methyl rosmarinate: the former being earlier described in D. moldavica (Kakasy et al. 2006), D. peregrinum (Dai et al. 2008) and D. ruyschiana (Kakasy et al. 2006), and the latter in aerial parts of D. moldavica (Yang et al. 2013). However, our work is the first report to describe the presence of salvianolic acids such as $\mathrm{B}, \mathrm{I} / \mathrm{H}, \mathrm{E}$ and lithospermic acid A in the shoots of $D$. forrestii. Our previous studies have reported significant amounts of salvianolic acid B in transformed root cultures and the roots of a 1-year-old intact plant of D. forrestii (Weremczuk-Jeżyna et al. 2016). In contrast to caffeic and rosmarinic acid, salvianolic acids are not common and have been found in only a few species (Ożarowski et al. 2016; Ribeiro et al. 2016; Cirlini et al. 2016). They are mainly obtained from members of the Salvia genus, especially Salvia milthiorrhiza (Li et al. 2009a). Our results also include the first description of dicaffeoylquinic acid in $D$. forrestii shoots.

\section{Effect of cytokinins on metabolite accumulation}

The UHPLC analysis showed that the secondary metabolite levels in the individual extract of $D$. forrestii shoots depended on the type and concentration of the applied cytokinins. However, the most common compounds in all analyzed materials were rosmarinic acid and salvianolic acid B. RA and SAB biosynthesis was much greater in multiplied shoots cultured in media containing any cytokinin, at almost all tested concentrations excluding $0.1 \mu \mathrm{M}$ TDZ and $1 \mu \mathrm{M}$ zeatin, compared to those grown on control MS medium without cytokinin (Figs. 2, 3). In the present study, a reverse relationship between the in vitro shoot proliferation and the production of RA and SAB was observed, especially for media that contained BAP. Phytohormones may stimulate the growth of the culture, but it did not have to be correlated with the production of active metabolites in plant biomass (Stalman et al. 2003; Collin 2001). Although the highest used concentrations of BAP $(8$ and $16 \mu \mathrm{M})$ correlated with the greatest $D$. forrestii shoot proliferation, they were not so effective for phenolic acid accumulation. In our investigation, the highest RA content $(18.7 \mathrm{mg} / \mathrm{g} \mathrm{DW})$ was found in $D$. forrestii shoots multiplied on MS medium supplemented with $2 \mu \mathrm{M}$ BAP and $1 \mu \mathrm{M}$ IAA. The level of RA was nine times higher than in shoots grown on control medium $(2.12 \mathrm{mg} / \mathrm{g} \mathrm{DW})$ and five times higher than in aerial parts of 1-year-old intact plants $(3.81 \mathrm{mg} / \mathrm{g} \mathrm{DW})$. Supplementation of the medium with $2 \mu \mathrm{M}$ BAP was also effective for $\mathrm{SAB}$ accumulation $(5.6 \mathrm{mg} / \mathrm{g} \mathrm{DW})$. Similarly, the lowest level of BAP $(0.5 \mathrm{mg} / \mathrm{l})$ induced the greatest biosynthesis of phenolic compounds in shoot culture of Thymus vulgaris, meanwhile higher BAP concentrations ( 2 and $4 \mathrm{mg} / \mathrm{l}$ ) stimulated the production of metabolites in the species at a lower level (Karalija and Parić 2011). Grzegorczyk-Karolak et al. (2015) also report that lower $(2 \mu \mathrm{M})$ BAP concentration was more efficient for biosynthesis of flavonoids and verbascoside in shoots culture of S. alpina.

Different types and concentrations of growth regulators can be employed to improve growth and bioactive compound accumulation in plant cultures. The increased production of secondary metabolites could be attributed to differential mechanism by which cytokinins influence biosynthesis. The growth regulators could affect the expression of specific genes by regulating the abundance of individual proteins (Taha et al. 2008). On the other hand, Endress (1994) postulated that the mechanism of action of the cytokinins is based on scavenging free radicals or reducing their formation to very low amounts. The free radicals affect on phospholipids 
and reduce membrane integrity. Thus, cytokinins stabilize membranes and could influence the exportation of necessary amino acids.

It is often observed that BAP has a strong influence on secondary metabolite biosynthesis in plant in vitro cultures compared to other cytokinins. For example, the presence of BAP was more favorable for harpagide accumulation in shoot culture of Rhemannia elata than kinetin and $2 \mathrm{iP}$ (2-isopentenyladenine) (Piątczak et al. 2015). Similarly, BAP stimulated biomass growth and isoflavonoid production in callus culture of Genista tinctoria (Euczkiewicz et al. 2014) and silymarin biosynthesis in shoot culture of Silybum marianum (Al-Hawuamdeh et al. 2013). However, the most potent determinant of the appropriate cytokinin selection is the species of cultivated plant. Therefore, zeatin was found to be the growth regulator that increased isoflavonoid biosynthesis in Glycyrrhiza glabra suspension culture (AriasCastro et al. 1993) and had a positive effect on hypericin production in Hypericum sampsonii shoots (Liu et al. 2007c), whereas TDZ stimulated the production of polyphenolic compounds in shoot culture of Scutelaria altissima (Grzegorczyk-Karolak et al. 2017) and in shoot cultures of Phyllanthus amarus (Nitnaware et al. 2011). While our findings suggest that supplementation of growth medium with zeatin was the least favorable factor for increasing SAB and RA biosynthesis in D. forrestii shoots (Figs. 2, 3), thidiazuron significantly enhanced $\mathrm{SAB}$ production. In the presence of 0.5 and $1 \mu \mathrm{M}$ TDZ, $D$. forrestii shoots biosynthesized between 5.5 and $6 \mathrm{mg}$ salvianolic acid B per g DW which was about 11 times greater than in the shoots cultured on MS medium without cytokinins (0.5 mg/g DW) (Figs. 2, 3). However, the amount was slightly lower than in the aerial parts of 1-year-old naturally grown plants $(8.87 \mathrm{mg} / \mathrm{g} \mathrm{DW})$. These results complies with those of a previous study which found that $D$. forrestii transformed root cultures were worse sources of SAB than the root of naturally-grown plants (Weremczuk-Jeżyna et al. 2016). This suggests that in vitro conditions are more favorable for production of rosmarinic acid than its dimer, SAB.

\section{Conclusion}

The present study describes the first proliferation protocol for the valuable medical plant $D$. forrestii. The regeneration of shoots from nodal segments is a simple method, which could be potentially used for effective mass propagation. Our findings clearly indicate that cytokinins could be important factor that determine growth and accumulation of bioactive metabolites. Of the cytokinins used in the study, BAP was the most effective for inducing shoot multiplication and metabolite production. In addition, it was found that the multiplied shoots of $D$. forrestii are rich sources of polyphenolic compounds. Our findings identified nine compounds, five of which are described in the species for the first time. The predominant metabolites in the shoot cultures were RA and $\mathrm{SAB}$. In vitro culture has proven to be a particularly advantageous technique for obtaining rosmarinic acid, whose content, under optimal conditions, was found to be five times higher in the cultures than in the aerial parts of naturally growing plants of $D$. forrestii. Further studies are needed to evaluate the accumulation of other compounds in $D$. forrestii shoots and identify the relationships between growth condition and productivity in the culture.

Author contribution statement IW-J obtained shoots of $D$. forrestii and studied influence of cytokinins on their proliferation, also prepared samples for UHPLC and UPLCPDA-ESI-MS and wrote this article. $€ K$ performed UHPLC analysis. AKK performed UPLC-PDA-ESI-MS analysis. IG-K analyzed MS chromatograms and was responsible for verification of the paper. All authors read and approved the manuscript.

Open Access This article is distributed under the terms of the Creative Commons Attribution 4.0 International License (http://creativeco mmons.org/licenses/by/4.0/), which permits unrestricted use, distribution, and reproduction in any medium, provided you give appropriate credit to the original author(s) and the source, provide a link to the Creative Commons license, and indicate if changes were made.

\section{References}

Affonso VR, Bizzo HR, Lage CLS, Sato A (2009) Influence of growth regulators in biomass production and volatile profile of in vitro plantlets of Thymus vulgaris. J Agric Foot Chem 57:6392-6395. https://doi.org/10.1021/jif900816c

Al-Hawuamdeh FM, Shibili RA, Al-Qudah TS (2013) In vitro production of silymarin from Silybum marianum L. Med Aromat Plants. https://doi.org/10.4172/2167-01412.S1-001

Arias-Castro C, Scragg AH, Staford A, Rodriquez-Mendiola M (1993) Growth characteristic of Glycyrrhiza glabra cell suspension cultures. Plant Cell Tissue Org Cult 34:77-82. https://doi. org/10.1007/BF00048466

Bulgakov VP, Inyushkina YV, Fedoreyev S (2012) Rosmarinic acid and its derivatives: Biotechnology and applications. Crit Rev Biotechnol 32:203-217. https://doi.org/10.3109/07388551.2011.596804

Cao W, Guo X, Zheng H, Li D, Jia G, Wong I (2012) Current progress of research on pharmacological actions of salvianolic acid B. Chin J Int Med 18:316-320

Carlotto J, da Silva LM, Dartora N, Ferreira DM, de A Sabry, Filho D, de Paula Werner APS, Sassaki MF, Gorin GL, Iacomini PAJ, Ciprioni M, de Suza TR LM (2015) Identification of a caffeoylquinic acid isomer from Arctium lappa with potent anti-ulcer activity. Talanta 135:50-57. https://doi.org/10.1016/j.talanta.2014.11.068

Catarino MD, Silva AMS, Saraiva SC, Sabral AJFN, Cardoso SM (2015) Characterization of phenolic constituents and evaluation of antioxidant properties of leaves and stems of Eriocephalus africanus. Arab J Chem. https://doi.org/10.1016/j.arabic2015.04.018 
Chen F, Long X, Liu Z, Shao H, Lu L (2014) Analysis of phenolic acids of Jerusalem Artichoke (Helianthus tuberosus L.) responding to salt-stress by liquid chromatography/tandem mass spectrometry. Sci World J. https://doi.org/10.1155/2014/568043

Cirlini M, Mena P, Tossatti M, Herhinger KA, Nieman KM, Dall'Asta C, DelRio D (2016) Phenolic acid volatile composition of dry spearmint (Mentha spicata L.) extract. Molecules 21:1007-1021. https://doi.org/10.3390/molecules21081007

Collin HA (2001) Secondary product formation in plant tissue cultures. Plant Growth Regul 34:119-134. https://doi.org/10.1023/A:10133 74417961

Dai LM, Zhao CC, Jin HZ, Tang J, Shen YH, Li HL, Zhang WD (2008) A new ferulic acid ester and other constituents from Dracocephalum peregrinum. Arch Pharm Res 31(10):1325-1329. https://doi. org/10.1007/s12272-001-2113-2

Dong J, Wan G, Liang Z (2010) Accumulation of salicylic acidinduced phenolic compounds and raised activities of secondary metabolic and antioxidative enzymes in Salvia miltiorrhiza cell culture. J Biotechnol 148:99-104. https://doi.org/10.1016/j.jbiot ec.2010.05.009

Endress R (1994) Plant cell biotechnology. Springer, Berlin

Fattahi M, Nazeri V, Torras-Claveria L, Sefidkon F, Cusiod RM, Zamani Z, Palazon J (2013) A new biotechnological source of rosmarinic acid and surface flavonoids; hairy roots cultures of Dracocephalum kotschyi Boiss. Ind Crops Prod 50:256-263. https ://doi.org/10.1016/j.jbiotec.2010.05.009

Fraternale D, Giamperi L, Ricci D, Rocchi MBL, Guidi L, Epifano F, Marcotullio MC (2003) The effect of triacontanol of micropropagation and on secondary system of Thymus mastichina. Plant Cell Tissue Org Cult 74:87-97. https://doi.org/10.1023/A:10233 21024040

Ghandi K, Kariraj CP, Venugopal RB, Jabeen FTZ, Rao S (2004) Rapid regeneration of Mentha piperita $\mathrm{L}$. from shoot tip and nodal explants. Indian J Biotechnol 3:594-598

Grzegorczyk-Karolak I, Kuźma Ł, Wysokińska H (2015) The effect of cytokinins on shoot proliferation, secondary metabolite production and antioxidant potential in shoot cultures of Scutellaria alpina. Plant Cell Tissue Org Cult 122:699-708. https://doi. org/10.1007/s11240-015-0804-5

Grzegorczyk-Karolak I, Kuźma Ł, Wysokińska H (2017) The influence of cytokinins of proliferation and polyphenol accumulation in shoot cultures of Scutellaria altissima L. Phytochem Lett 20:449-455. https://doi.org/10.1016/j.phytol.2016.12.029

Hur YG, Suh CH, Kim S, Won J (2007) Rosmarinic acid induces apoptosis of activated $\mathrm{T}$ cells from rheumatoidal arthritis patients via mitochondrial pathway. J Clin Immunol 27:36-45. https://doi. org/10.1007/s10875-006-9057-8

Inyunshina YV, Bulgakov VP, Veselova MV, Bryukhanov VM, Zverev YF, Lampatov VV, Azarova OV, Tchemoded GK, Fedoreyev SA, Zhuravlev YN (2007) High rabdosin and rosmarinic acid production in Eritrichium sericeum callus cultures and the effect of the calli on Masugi-nephritis in rats. Biosci Biotechnol Biochem 71:1286-1293. https://doi.org/10.1271/bbb60684

Jaiong RW, Lou KM, Hon PM, Mak TC, Woo KS, Fung KP (2005) Chemistry and biological activities of caffeic acid derivatives from Salvia miltiorrhiza. Curr Med Chem 12:237-246. https:// doi.org/10.2174/0929867053363397

Kakasy A, Füzfai Z, Kursinszki L, Molnár-Perl I, Lemberkovics É (2006) Analysis of non-volatile constituents in Dracocephalum species by HPLC and GC-MS chromatographia.63: S17-S22. https://doi.org/10.1365/s10337-006-0741-x

Karalija E, Parić A (2011) The effect of BA and IBA on the secondary metabolite production by shoot culture of Thymus vulgaris. Biol Nyssana 2:29-35
Kuo YH, Lee SM, Lai JS (2000) Constituents of the whole herb of Clinopodium laxiflorum. J Chin Chem Soc Taip 47:241-246. https ://doi.org/10.1002/jccs.200000028

Lecompte J, Giraldo LJL, Laguerre M, Baréa B, Villeneuve P (2010) Synthesis, characterization and free radical scavenging properties of rosmarinic acid fatty ester. J Am Oil Soc 87:615-620. https:// doi.org/10.1007/s11746-010-1543-8

Li GP, Zhao JF, Yang LY, Yang XD, Li L (2007) New monoterpenoids from Dracocephalum forrestii aerial parts. Ind J Chem 468:1352-1354

Li YG, Song L, Liu M, Hu ZB, Wong ZT (2009a) Advancement in analysis of Salviae miltiorrhizae radix et rhizome (Danshen). J Chromatogr A 1216:1941-1953. https://doi.org/10.1016/j.chrom a.2008.12.032

Li SM, Yang XW, Li YL, Shen YH, Feng 1, Wang YH, Zeng HW, Liu XH, Zhang CS, Long CL, Zhang WD (2009b) Chemical constituents of Dracocephalum forrestii. Planta Med 75:1591-1596. https ://doi.org/10.1055/s-0029-1185868

Li GS, Jiang WI, Tian JW, Qu GW, Zhu HB, Fu FH (2010) In vitro band in vivo antifibrotic effects of rosmarinic acid on experimental liver fibrosis. Phytomedicine 17:282-288. https://doi. org/10.1016/j.phymed.2009.05.002

Liu AH, Guo H, Ye M, Lin YH, Sun JH, Xu M, Guo DA (2007a) Detection characterization and identification of phenolic acids in Danshen using high-performance liquid chromatography with diode array detection and electrospray ionization mass spectrometry J Chromatogr A 1161: 170-182. https://doi.org/10.1016/j. croma.2007.05.08

Liu AH, Liu YH, Yong M, Guo H, Guan SH, Su JM, Guo DA (2007b) Development of the fingerprints for the quality of the roots Salvia miltiorrhiza and its related preparations by HPLC-DAD and LC-MS(n). J Chromatogr B 856:32-41. https://doi.org/10.1016/j. jchromb.2006.08.002

Liu XN, Zhang XQ, Sun JS (2007c) Effect of cytokinins and elicitors on the production of hypericins and hyperforin metabolites in Hypericum sampsonni and Hypericum perforatum. Plant Growth Regul 53:207-214. https://doi.org/10.1007/s10725-007-9220-0

Łuczkiewicz M, Kokotkiewicz A, Gold D (2014) Plant growth regulators effect biosynthesis and accumulation profile of isoflavone phytoestrogens in high-productive in vitro culture of Genista tinctoria. Plant Cell Tissue Org Cult 118:419-429. https://doi. org/10.1007/s1240-014-0494-4

Mehta J, Naruka R, Sain M, Dwiredi A, Sharma D, Mirza J (2012) An efficient protocol for clonal micropropagation of Mentha piperita L. (Pipperment). Asian J Plant Sci Res 2:518-523

Murashige T, Skoog F (1962) A revised medium for rapid growth and bioassay with tobacco tissue culture. Physiol Plant 15:473-497. https://doi.org/10.1111/j.1399-3054.1962.tb08052.x

Ncube N, Mhlongo MI, Piater LA, Steenkamp PA, Dubery IA, Madala NE (2014) Analyses of chlorogenic acids and related cinnamic acid derivatives from Nicotiana tabacum tissues with the aid of UPLC-QTOF-MS/MS based on the in-source collisioninduced dissociation method. Chem Cent J 8:66-76. https://doi. org/10.1186/s13065-014-0066-Z

Nitnaware KM, Naik DG, Nikam TD (2011) Thidiazuron-induced shoot organogenesis and production of hepatoprotective lignin phyllanthin and hypophyllanthin in Phyllanthus amarus. Plant Cell Tissue Org Cult 104:101-110. https://doi.org/10.3923/ pjbs.2017.328.335

Nuenchamong N, Krittasilp K, Ingkaniiaran K (2011) Characterization of phenolic antioxidants in aqueos extract of Orthosiphon grandiflorus tea by LC-ESI-MS/MS coupled to DPPH assay. Food Chem 127: 1287-1293. https://doi.org/10.1016/j.foodchem.2011.01.085

Otroshy M, Moradi K (2013) Rapid regeneration of Dracocephalum kotschyi Boiss. from nodal explants. Int Life Sci Med Res 3:1114. https://doi.org/10.5963/LSMR0301002 
Ożarowski M, Mikołajczyk PL, Piasecka A, Kawińska E, Kujawska R, Bogacz A, Bartkowiak-Wieczorek J, Szulc M, Kamińska E, Kujawska M, Jodynis-Liebert J, Gruszczyńska AA, Opala B, Lowicki Z, Seremak-Mrozikiewicz A, Czerny B (2016) Influence of the Melissa officinalis leaf extract on long term memory in scopolamine animal model with assessment of mechanism of action. Evid Bored Complement Alternat Med 2016:9729818. https://doi. org/10.1155/2016/9729818

Petersen M (2013) Rosmarinic acid: new aspects. Phytoch Rev 12:207227. https://doi.org/10.1007/s11101-013-9282-8

Piątczak E, Talar A, Kuźma Ł, Wysokińska H (2015) Iridoid and phenylethanoid glycoside production in multiple hoots and regenerated Rehmannia elata N.E. Brown ex Prain plants following micropropagation. Acta Pysiol Plant 37:233-255. https://doi. org/10.1007/s11738-015-2011-8

Rani G, Talwar D, Nagpal A, Virk GS (2006) Micropropagation of Coleus blumei from nodal segments and shoot tips. Biol Plant 50:496-500. https://doi.org/10.1007/s10535-006-0078-1

Ribeiro A, Caleja C, Barros L, Santos-Buelga C, Barreiro MF, Ferreira ICFR (2016) Rosemary extracts in functional foods: extraction, chemical characterization and incorporation of free and microencapsulated forms in cottage cheese. Food Funct 27:2182196. https ://doi.org/10.1039/C6FO00270F

Santos-Gomes PC, Fernandes-Ferreira M (2003) Essential oil produced by in vitro shoots of sage (Salvia officinalis). J Agric Food Chem 51:2260-2266. https://doi.org/10.1021/jf020945v

Stalman M, Koskamp AM, Luderer R, Vernooy JHJ, Wind JC, Wullmes GJ, Craes AF (2003) Regulation of anthraquinone biosynthesis in cell cultures of Morinda citrifolia J. Plant Physiol 160:607-614. https://doi.org/10.1078/0176-1617-00773

Tada H, Murakami Y, Omoto T, Shimomura K, Ishimaru K (1996) Rosmarinic acid and related phenolic in hairy root cultures of Ocimum basilicum. Phytochem 42:431-432. https://doi.org/10.1016/00319422(96)00005-2

Taha HS, Abdul El-Rahman RA, Fathalla M, Abdul El-Kareem MA, Aly UE(2008) Successful application for enhancement and production of anthocyanin pigment from calli cultures of some ornamental plants. Aust J Basic Appl Sci 4:1148-1156
Tisserot B, Vanghn S (2008) Growth, morphogenesis and essential oil production in Mentha spicata L. plantlets. In Vitro Cell Dev Biol 44:40-44. https://doi.org/10.1007/s11627-007-9077-y

Wang S, Liu L, Wang L, Hu Y, Zhong W, Liu K (2012) Structural characterization and identification of major constituents in Jitai tablets by high-performance liquid chromatography/diode- array detection complied with electrospray ionization Tandem mass Spectrometry. Molecules 17: 10470-10483. https://doi.org/10.3390/ molecules 170910470

Weremczuk-Jeżyna I, Grzegorczyk-Karolak I, Frydrych B, Królicka A, Wysokińska H (2013) Hairy roots of Dracocephalum moldavica: rosmarinic acid content and antioxidant potential. Acta Physiol Plant 35:2095-2103. https://doi.org/10.1007/s11738-013-1244-7

Weremczuk-Jeżyna I, Skała E, Olszewska MA, Kiss AK, Balcerczak E, Wysokińska H, Kicel A (2016) The identification and quantitative determination of rosmarinic acid and salvianolic acid B in hairy root cultures of Dracocephalum forrestii W.W. Smith. Ind Crop Prod 91:125-131. https://doi.org/10.1016/jindcrop.2016.07.002

Xiao Y, Gao S, Di P, Chen J, Chen W, Zhang I (2010) Lithospermic acid $\mathrm{B}$ is more responsive to silver ions $\left(\mathrm{Ag}^{+}\right)$than rosmarinic acid in Salvia miltiorrhiza hairy root cultures. Biosci Rep 30:33-40. https://doi.org/10.1042/BSR2008012

Yang L, Yan Q, Mo H, Li X, Wong Q (2012) Determination of chlorogenic acid, baicalin and forsythin in shuanghuanglian preparations by HPLC-DAD. J Chil Chem Soc 57:1361-1363. https://doi. org/10.4067/S0717-97072012000400006

Yang S, Wang L, Guo X, Lou H, Ren D (2013) A new flavonoid glycoside and other constituents from Dracocephalum moldavica. Nat Prod Res 27:201-207. https://doi.org/10.1080/14786 419.2012.666746

Zeng G, Xiao H, Liu J, Liang X (2006) Identification of phenolic constituents in Radix Salvia miltiorrhiza by liquid chromatography/ electrosprayionization mass spectrometry. Rapid Commun Mass Spectrum 20: 499-506. https://doi.org/10.1002/rcm.2332

Zeng Q, Jin HZ, Quin JJ, Fu JJ, Hu XJ, Liu JH, Yan L, Chen M, Zhang WD (2010) Chemical constituents of plants from the genus Dracocephalum. Chem Biodivers 7:1911-1928. https://doi. org/10.1002/cbdv.200900188 